\title{
Betydningen av feilstilling etter dorsalt vinklet distal radiusfraktur
}

BAKGRUNN Distale radiusbrudd er meget hyppig. De fleste er vinklet dorsalt (Colles' fraktur). I motsetning til tidligere blir nå omtrent en firedel av pasientene operert. Dette er flere enn det er som blir reponert og gipset. Volar plateosteosyntese er nå den vanligste formen for kirurgi. Det er stor usikkerhet omkring indikasjoner for kirurgi.

KUNNSKAPSGRUNNLAG Artikkelen er basert på egen forskning, et søk i PubMed og gjennomgang av referanselistene for å identifisere artikler som sammenholder det røntgenologiske og det kliniske resultatet etter Colles' fraktur.

RESULTATER Litteraturen er gjennomgått av flere nasjonale ortopediske foreninger i fors $ø \mathrm{k}$ på å utarbeide retningslinjer for operasjonsindikasjoner for distal radiusfraktur - uten at man har kunnet komme med sikre anbefalinger basert på randomiserte studier. Gjennomgang av samlematerialer indikerer svært usikker sammenheng mellom røntgenfeilstilling og endelig klinisk resultat. Særlig gjelder dette for eldre pasienter (over 55-65 år), der man i en overveldende stor andel av studiene ikke finner noen slik sammenheng. Komplikasjoner og reoperasjoner er vanlig hos dem som er operert med volar plate.

FORTOLKNING Det er forbausende liten sammenheng mellom det røntgenologiske og det kliniske utfallet etter Colles' fraktur. En praksis der en stor andel opereres, er neppe berettiget. Eldre pasienter vil svært sjelden på sikt tjene på operasjon.

Distal radiusfraktur er det vanligste bruddet som behandles av helsevesenet (1). Det store flertallet er vinklet dorsalt (fractura radii typica - Colles' fraktur) (2). Frem til for et par tiår siden var de fleste klinikere enige om at håndleddet etter et slikt brudd etter hvert ville gjenvinne utmerket funksjon (3-5). Nesten alle tilfeller av Colles' fraktur ble behandlet konservativt, selv om feilstillingen på røntgen etter reposisjon kunne være betydelig. I løpet av de siste tiårene er det blitt lagt større vekt på betydningen av å gjenopprette anatomisk stilling i skjelettet for å oppnå et godt klinisk resultat. På tross av mange studier er det fortsatt uavklart hvilke feilstillinger som er akseptable. De nasjonale ortopediske foreningene i Danmark (6), USA (7) og Norge har foreløpig ikke kunnet komme med sikre anbefalinger.

Det finnes flere kirurgiske behandlingsalternativer. I løpet av de siste årene er det blitt stadig vanligere å velge åpen reposisjon og fiksasjon med plate og vinkelstabile skruer. I USA er det over 30 forskjellige slike implantater å velge mellom $(8,9)$. Utvalget er også stort i Norge.

På tross av de usikre indikasjonene er det ikke tvil om at andelen som blir operert har øt kraftig. I et materiale fra Sverige ble 220 av 518 pasienter med distale radiusfrakturer behandlet med gipsing uten reposisjon, mens 212 ble behandlet primært med reposisjon og gips (10). Totalt ble 133 av pasientene i dette materialet $(26 \%)$ operativt behandlet, hvorav 86 primært. Dette er sannsynligvis representativt også for norsk praksis. En journalgjennomgang viste at vi ved St. Olavs hospital i 2009 og 2010 opererte omkring en firedel av pasientene, flere enn vi behandlet med reposisjon og gips (eget, upublisert materiale).

Hvis man ser bort fra allmenntilstanden, vil graden av røntgenologisk feilstilling $\mathrm{i}$ bruddet være det viktigste momentet for å anbefale operasjon. De vanligste måtene å beskrive feilstillingen på er vist $\mathrm{i}$ figur 1 . Videre vurderes graden av fragmentering av distale fragment og eventuelle ujevnheter $i$ leddflaten.

Formålet med denne artikkelen er å oppsummere tilgjengelig kunnskap vedrørende sammenhengen mellom feilstilling etter Colles' fraktur og det kliniske utfallet.

\section{Kunnskapsgrunnlag}

Denne oversikten er basert på egen forskning og på et søk i PubMed for perioden 1995 til medio 2011. Artikler på de skandinaviske språk og på engelsk, spansk, tysk og fransk som omhandlet det kliniske utfallet etter konservativt behandlet Colles' fraktur ble identifisert ut fra tittel og sammendrag. Videre ble relevante artikler funnet ved gjennomgang av referanselister og i eget artikkelarkiv.

\section{Vurdering av det kliniske utfallet}

Vurderingen av det kliniske resultatet ble tidligere overlatt til kirurgen. Gartland \& Werley (11) innførte et objektivt skåringssystem i 1951, som siden er modifisert av flere (12-14). Ingen av versjonene er validert (15).

Senere er det kommet flere validerte, rent subjektive skåringer der pasienten på egen hånd besvarer et sett med spørsmål. Det

\author{
Vilhjalmur Finsen \\ vilh.finsen@ntnu.no \\ Det medisinske fakultet \\ Norges teknisk-naturvitenskapelige universitet \\ og \\ Ortopedisk avdeling \\ St. Olavs hospital \\ Øyvind Rød \\ Kristian Rød \\ Benjamin Rajabi \\ Pål Sandøe Alm-Paulsen \\ Det medisinske fakultet \\ Norges teknisk-naturvitenskapelige universitet \\ Harald Russwurm \\ Ortopedisk avdeling \\ St. Olavs hospital
}

\section{HOVEDBUDSKAP}

Brudd i nedre radiusende er den vanligste frakturen som behandles i helsevesenet

I motsetning til tidligere er det i dag flere som blir operert enn reponert og gipset

Litteraturen viser liten sammenheng mellom feilstilling ved tilheling og det kliniske utfallet etter dorsalt vinklede frakturer

Få pasienter med brudd i nedre radiusende, særlig hvis de er over 55-65 år, vil sannsynligvis på sikt være tjent med operasjon 


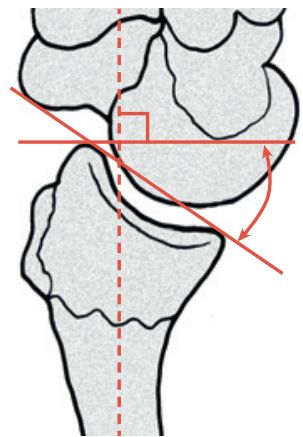

Dorsal vinkling
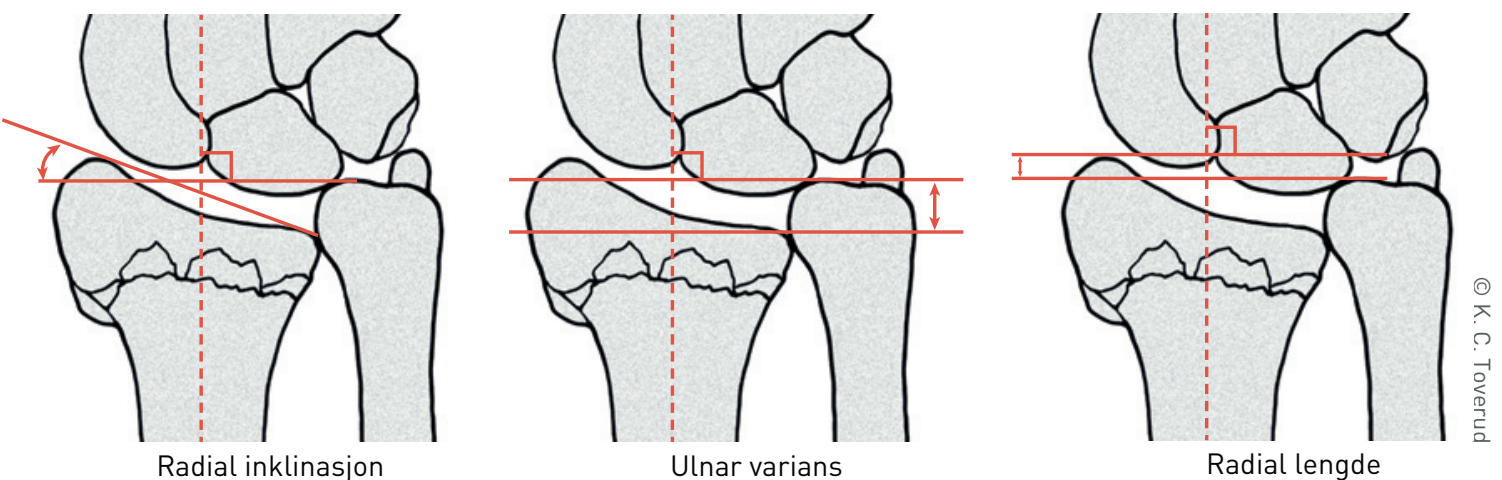

Figur 1 Vanlige røntgenmål. Dorsal vinkling måles i sideprojeksjon i forhold til radius' lengdeakse. Radial inklinasjon er helningsvinkelen på radius' artikulasjonsflate i frontalprojeksjon i forhold til radius' lengdeakse. Forkorting av radius uttrykkes oftest som ulnar varians, men noen ganger som radial lengde

mest brukte er DASH-skjemaet (dysfunksjon i arm, skulder og hånd) (16), som består av 30 spørsmål, og kortversjonen av det, Kvikk-DASH (K-DASH), som består av 11 av spørsmålene $(17,18)$. Spørsmålene dreier seg om smerte og funksjon ved bruk av begge armer. Et annet validert vanlig brukt skåringssystem er PRWE-skjemaet (patient rated wrist evaluation), som består av 15 spørsmål om smerte og funksjon kun relatert til den skadede armen $(15,19)$.

\section{Faktorer av betydning}

\section{i uselekterte pasientgrupper}

Fysioterapi kan bedre det kliniske resultatet (20). Noen har funnet at uavklarte erstatningssøksmål $(21,22)$, utdanningslengde (21) og inntektsnivå (23) er faktorene med størst betydning for det kliniske utfallet. De fleste antar likevel at som ved de fleste andre brudd er gjenoppretting av anatomisk stilling i skjelettet viktig for å oppnå et godt resultat.

Vi har nylig etterundersøkt 260 pasienter med konservativt behandlet Colles' fraktur (24). Mange av bruddene hadde grodd i betydelig feilstilling. Gjennomsnittlig VASskår for smerte den foregående uken var 6 (SD 15) på en skala fra 0 til 100. Det kliniske utfallet, målt med både K-DASH- og PRWE-skjemaet, korrelerte statistisk signifikant med hver av de tre røntgenmålene på feilstilling (fig 1) ved etterkontroll og også med tid fra skade til etterundersøkelse, om det hadde vært skade av processus styloideus ulnae og om det hadde vært komplikasjoner. Det korrelerte ikke signifikant med alder eller bruddtype, om det hadde vært bruddlinjer inn i distale radioulnarledd, om det var ujevnheter i radius' leddflate eller om bruddet bare hadde vært gipset eller også reponert. Når alle faktorer ble tatt med i en lineær regresjonsanalyse, bidro de bare til å forklare $20 \%$ av PRWE-skårene og $16 \%$ av K-DASH-skårene. Regresjonsanalyse med bare de tre røntgenologiske målene på feilstilling som uavhengige variabler viste at disse til sammen bidro med forklaring av $6 \%$ av PRWE- og $7 \%$ av K-DASH-skårene.

Vi har identifisert 25 andre studier der man har sett på sammenhengen mellom det røntgenologiske og det kliniske resultatet hos uselekterte pasienter. I seks studier kunne man ikke finne at noen av de tre røntgenmålene hadde betydning $(4,10,14,22$, $23,25)$, i åtte fant man at dorsal vinkling var av betydning $(3,26-32)$. Konklusjonen i tre studier var at det går en grense mellom godt og dårlig utfall ved $10^{\circ}$ dorsal vinkling (26, $29,32)$, i tre andre at grensen går ved $15^{\circ}(3$, $28,31)$.

I seks studier var konklusjonen at radial inklinasjon er av betydning (3, 29-31, 33, 34 ). I to mente man å kunne påvise en grense ved $15^{\circ}$ gjenværende radial inklinasjon (29, $34)$, i én en grense ved $10^{\circ}(31)$ og i en annen en grense ved $5^{\circ}(3)$.

I 16 studier fant man at forkorting av radius (økt ulnar varians) var av betydning for resultatet $(3,5,27-32,34-41)$. Konklusjonen $i$ to studier var at det gikk et skille ved $2 \mathrm{~mm}$ ulnar varians $(31,41)$, i to andre gikk skillet ved $3 \mathrm{~mm}(28,29)$ og i én gikk det ved $5 \mathrm{~mm}(3)$.

I en fersk oversiktsartikkel skrev Jesse Jupiter \& Asif M. Ilyas at ved lukkede brudd uten annen skade er radial inklinasjon på mer enn $15^{\circ}$, radiusforkorting på $5 \mathrm{~mm}$ eller mindre, dorsal vinkling på mindre enn $15^{\circ}$ og intraartikulære trinn i leddflaten på mindre $2 \mathrm{~mm}$ akseptable feilstillinger etter reposisjon av Colles' fraktur (42). Jesse Jupiter er en nestor i operativ behandling av distale radiusbrudd.

The American Academy of Orthopedic Surgeons gjennomgikk nylig litteraturen. De fant bare moderat bevis til støtte for operativ fiksasjon av brudd hos unge mennesker som etter reposisjon hadde radiusforkorting på over $3 \mathrm{~mm}$, dorsal vinkling på over $10^{\circ}$ eller intraartikulær feilstilling på over $2 \mathrm{~mm}$ sammenliknet med gipsbehandling (7). De fant ikke grunnlag for å trekke noen konklusjoner overhodet når det gjaldt operasjon av pasienter over 55 år.

\section{Eldre pasienter}

Det finnes en rekke studier der man har sett på forholdene spesielt hos eldre, og i svært få er det sammenheng mellom røntgenfeilstil- ling og klinisk resultat. I to studier med til sammen 80 pasienter ble gipsbehandling randomisert mot ekstern fiksasjon - uten bedret klinisk resultat $(43,44)$. I den ene (44) rapporterte 43 pasienter over 55 år med brudd som hadde redislokert i gips. De ble randomisert til enten videre gipsbehandling uten ny reposisjon eller ny reposisjon og ekstern fiksasjon. Etter seks måneder var det bedre stilling på røntgenbildene i gruppen med ekstern fiksasjon, men ikke bedre funksjon.

Egol og medarbeidere sammenliknet 44 pasienter over 65 år som var blitt operert med 46 pasienter som var blitt behandlet konservativt (45). Ett år etter bruddet hadde de opererte bedre røntgenbilder og bedre grepsstyrke, men DASH-skår, bevegelighet $\mathrm{i}$ håndleddet $\mathrm{og}$ smertenivå var den samme $\mathrm{i}$ begge gruppene.

Arora og medarbeidere anbefalte kirurgi til 114 pasienter over 70 år med brudd som hadde redislokert $\mathrm{i}$ gips til en stilling med over $20^{\circ}$ dorsal vinkling eller over $3 \mathrm{~mm}$ forkorting av radius eller der det var en ujevnhet i radius' artikulasjonsflate på over $2 \mathrm{~mm}$ (46). 61 ville ikke ha kirurgi og fortsatte med konservativ behandling uten ny reposisjon av bruddet (gjennomsnittlig observasjonstid 53 måneder), 53 ble operert med volar plate og vinkelstabile skruer (gjennomsnittlig observasjonstid 62 måneder). Ved etterundersøkelse var det ingen signifikante forskjeller mellom gruppene med henblikk på bevegelighet $\mathrm{i}$ håndleddet, grepsstyrke og DASHeller PRWE-skår. VAS-skår viste signifikant høyere grad av smerte i den opererte gruppen.

Kelly og medarbeidere randomiserte 30 pasienter over 65 år med dorsal vinkling mellom $10^{\circ}$ og $30^{\circ}$ eller opptil $5 \mathrm{~mm}$ forkorting til enten reposisjon og gips eller bare gips (47). Tre måneder etter fjerning av gipsen var det ingen forskjell i gjennomsnittlig Gartland and Werley-skår mellom gruppene.

I åtte studier (29, 34, 48-54) med til sammen 498 pasienter var det ingen sammenheng mellom det røntgenologiske og det kliniske resultatet blant eldre, mens man i én studie (55) med 22 pasienter fant at $6 \mathrm{~mm}$ forkorting var assosiert med et dårlig klinisk resultat. 
I en litteraturoversikt fra 2011 fant DiazGarcia og medarbeidere 21 engelskspråklige artikler om behandling av pasienter over 60 år med ustabile brudd i distale radius (56). De konkluderte med at røntgenresultatet var dårligere med gips, men at de kliniske resultatene var de samme som hos dem som var operert.

\section{Diskusjon}

Det synes som om det at radiusfrakturer gror i feilstilling, har forbausende liten betydning for det endelige kliniske resultat. Omtrent alle grader av gjenværende feilstilling kan gi et godt klinisk resultat, mens det kan være dårlige resultater på tross av gjenopprettelse av normal anatomi. I en Cochrane-rapport fra 2003 (57) kunne man ikke engang sikkert konkludere hvorvidt reposisjon av bruddet var til gunst for pasientene.

I helsevesenet bestreber man at behandling skal være kunnskapsbasert. Dette er vanligvis uproblematisk når flere studier har vist at en metode er til nytte for pasienten. Det er langt vanskeligere å vise at en behandling som er i utstrakt bruk ikke er til nytte, særlig når den intuitivt virker fornuftig. For de aller fleste bruddtyper er det slik at resultatet blir bedre om man kan gjenopprette skjelettanatomien. Likevel er den meget rikholdige litteraturen temmelig entydig: I et stort antall studier har man lett etter gevinster ved å gjenopprette skjelettetanatomien - uten å finne dem. I de fleste av studiene der man fant en statistisk signifikant sammenheng mellom røntgenresultatene og de kliniske resultatene, nøyde man seg med en enkel korrelasjon. Dette gir ingen indikasjon på hvor viktig eller hvor stor effekten av denne faktoren er for det kliniske resultatet. I vår egen studie var det også en meget signifikant sammenheng ved enkel korrelasjon, mens innvirkningen av feilstillingen på det kliniske resultatet i virkeligheten var liten. Bare betydelig dislokerte frakturer hos yngre vil muligens bli bedre på sikt om de opereres. Det er gode studier som tyder på at selv dette ikke er riktig (40). Det synes uomtvistelig at eldre pasienter, som utgjør flertallet av dem med Colles' fraktur, på sikt sjelden vil tjene på et inngrep.

Det er imidlertid indikasjoner på at bedringen $i$ håndleddet går raskere om pasienten opereres med plate og vinkelstabile skruer $(8$, $23,58)$. De fleste vil også kunne unngå gips. Begge disse momentene er opplagt av verdi for pasienten, men må vurderes på bakgrunn av den økte risikoen for komplikasjoner (9, $31,49,59)$. I sin oversikt over pasienter over 60 år fant Diaz-Garcia og medarbeidere at det var $11 \%$ komplikasjoner som medførte reoperasjon hos dem som var operert med plate og skruer, mot $1 \%$ hos dem som var behandlet med reposisjon og gips (56). En enkel journalgjennomgang for 2009 og 2010 viste at vår komplikasjonsrate ved plateosteosyntese var enda litt høyere enn dette (eget, upublisert materiale). Eldre pasienter
Tabell 1 Grenser for akseptabel feilstilling etter reposisjon av dorsalt vinklet distal radiusfraktur ved St. Olavs hospital. Grensene er, i mangel av bedre data, basert på en gjennomgang av hovedsakelig retrospektive samlestudier. (Dorsal vinkling: sett i forhold til radius' lengdeakse)

Aldersgruppe

$\begin{array}{rrc}<65 \text { år } & 65-75 \text { år } & >75 \text { år } \\ 15 & 20 & 25 \\ 4 & 6 & 8 \\ 15 & 10 & 0 \\ 2 & 4 & 4\end{array}$

bør gjøres oppmerksom på risikoen for komplikasjoner før de lar seg operere.

Selv om det viktigste er å unngå at pasienter underkastes operasjoner som de har liten sjanse for å ha nytte av, er det også naturlig å peke på at et hardt presset helsevesen sannsynligvis vil kunne anvende sine midler på en mer hensiktsmessig måte om antallet operasjoner for Colles' fraktur ble redusert. Dette gjelder særlig eldre pasienter - det er muligens kun de få med de aller mest dislokerte frakturene som vil ha nytte av operasjon.

På tross av at litteraturen er til begrenset hjelp, må en stor avdeling ha retningslinjer for behandling av vanlige tilstander. Ved St. Olavs hospital er indikasjonene nå som vist $i$ tabell 1 . Skillet mellom unge og eldre er vilkårlig satt omkring vanlig pensjonsalder. Kriteriene for de eldre gruppene er valgt slik at bare de aller mest dislokerte frakturene vil bli vurdert operert, idet man tar hensyn til «biologisk alder». Som det fremgår er disse retningslinjene ikke basert på gode data. Når randomiserte studier ikke gir svar, blir man henvist til de mindre sikre, men langt fra verdiløse samlematerialene i litteraturen. Retningslinjene vil bli oppdatert dersom bedre data blir tilgjengelig.

Vi takker professor Leiv M. Hove, Det medisinske fakultet, Universitetet i Bergen, for hjelp til utarbeidingen av figurutkast.

\section{Vilhjalmur Finsen (f. 1946)}

er professor i ortopedisk kirurgi og seksjonsoverlege for håndkirurgi.

Forfatter har fylt ut ICMJE-skjemaet og oppgir følgende interessekonflikter: Han er medlem av ekspertpanel, betalt av Pfizer.

\section{Øyvind Rød (f. 1981)}

er turnuslege ved Helgelandssykehuset i Mosjøen.

Forfatter har fylt ut ICMJE-skjemaet og oppgir ingen interessekonflikter.

\section{Kristian Rød (f. 1983)}

er bachelor i teoretisk fysikk og medisinstudent.

Forfatter har fylt ut ICMJE-skjemaet og oppgir ingen interessekonflikter.

\section{Benjamin Rajabi (f. 1986)}

er medisinstudent og har verv i Norsk medisinstudentforening. Han jobber som juniorvakt ved Ortopedisk avdeling, St. Olavs hospital.

Forfatter har fylt ut ICMJE-skjemaet og oppgir ingen interessekonflikter.

\section{Pål Sandøe Alm-Paulsen (f. 1986)}

er turnuslege ved Sørlandet Sykehus Kristiansand.

Forfatter har fylt ut ICMJE-skjemaet og oppgir ingen interessekonflikter.

\section{Harald Russwurm (f. 1935)}

er spesialist i ortopedisk kirurgi, med spesialkompetanse i håndkirurgi. Han er pensjonert seksjonsoverlege i håndkirurgi.

Forfatter har fylt ut ICMJE-skjemaet og oppgir ingen interessekonflikter.

1. Sahlin $Y$. Occurrence of fractures in a defined population: a 1-year study. Injury 1990; 21: 158-60.

2. Hove LM, Fjeldsgaard K, Reitan R et al. Fractures of the distal radius in a Norwegian city. Scand J Plast Reconstr Surg Hand Surg 1995; 29: 263-7.

3. Altissimi M, Antenucci R, Fiacca C et al. Long-term results of conservative treatment of fractures of the distal radius. Clin Orthop Relat Res 1986; 206 : 202-10.

4. Smaill GB. Long-term follow-up of Colles's fracture. J Bone Joint Surg Br 1965; 47: 80-5.

5. Warwick D, Field J, Prothero D et al. Function ten years after Colles' fracture. Clin Orthop Relat Res 1993: 295: 270-4.

6. Hølmer P, Krøner K, Hansen TB et al. Referenceprogram vedrørende Colles frakturer. Klaringsrapport nr. 14/2001. København: Den Almindelige Danske Lægeforening, 2001.

7. Lichtman DM, Bindra RR, Boyer MI et al. Academy of Orthopaedic Surgeons clinical practice guideline on: the treatment of distal radius fractures. J Bone Joint Surg Am 2011; 93: 775-8

8. Chen NC, Jupiter JB. Management of distal radius fratures. J Bone Joint Surg Am 2007: 89 : 2051-62.

9. Downing ND, Karantana A. A revolution in the management of fractures of the distal radius? J Bone Joint Surg Br 2008; 90: 1271-5.

10. Abramo A, Kopylov P, Tägil M. Evaluation of a treatment protocol in distal radius fractures: a prospective study in 581 patients using DASH as outcome. Acta Orthop 2008; 79: 376-85.

11. Gartland JJ jr., Werley CW. Evaluation of healed Colles' fractures. J Bone Joint Surg Am 1951; 33-A: 895-907.

\section{Litteratur}


12. Sarmiento A, Pratt GW, Berry NC et al. Colles fractures. Functional bracing in supination. J Bone Joint Surg Am 1975; 57: 311-7.

13. Lucas GL, Sachtjen KM. An analysis of hand function in patients with colles' fracture treated by Rush rod fixation. Clin Orthop Relat Res 1981; 155: $172-9$

14. Stewart HD, Innes AR, Burke FD. Factors affecting the outcome of Colles' fracture: an anatomical and functional study. Injury 1985; 16: 289-95.

15. Changulani M, Okonkwo U, Keswani T et al. Outcome evaluation measures for wrist and hand: which one to choose? Int Orthop 2008; 32: 1-6

16. Hudak PL, Amadio PC, Bombardier C. Development of an upper extremity outcome measure: the DASH (disabilities of the arm, shoulder and hand) [corrected]. Am J Ind Med 1996; 29: 602-8.

17. Gummesson C, Ward MM, Atroshi I. The shortened disabilities of the arm, shoulder and hand questionnaire (QuickDASH): validity and reliability based on responses within the full-length DASH. BMC Musculoskelet Disord 2006; 7: 44.

18. Finsen $V$. Norsk versjon av DASH-skjemaet for undersøkelse av arm, skulder og hånd. Tidsskr Nor Legeforen 2008; 128: 1070.

19. MacDermid JC, Turgeon T, Richards RS et al. Patient rating of wrist pain and disability: a reliable and valid measurement tool. J Orthop Trauma 1998; 12: 577-86.

20. Kay S, McMahon M, Stiller K. An advice and exercise program has some benefits over natural recovery after distal radius fracture: a randomised trial. Aust J Physiother 2008; 54: 253-9.

21. Grewal R, MacDermid JC, Pope J et al. Baseline predictors of pain and disability one year following extra-articular distal radius fractures. Hand (NY) 2007: 2: 104-11.

22. MacDermid JC, Donner A, Richards RS et al. Patient versus injury factors as predictors of pain and disability six months after a distal radius fracture. J Clin Epidemiol 2002; 55: 849-54

23. Chung KC, Kotsis SV, Kim HM. Predictors of functional outcomes after surgical treatment of distal radius fractures. J Hand Surg Am 2007; 32: 76-83.

24. Finsen V, Rod O, Rød K et al. The relationship between displacement and clinical outcome after distal radius (Colles') fracture. J Hand Surg Eur 2012. E-publisert 2.6.

25. Kopylov P, Johnell O, Redlund-Johnell I et al. Fractures of the distal end of the radius in young adults: a 30-year follow-up. J Hand Surg [Br] 1993 18: $45-9$

26. Gliatis JD, Plessas SJ, Davis TR. Outcome of distal radial fractures in young adults. J Hand Surg [Br] 2000; 25: 535-43.

27. Batra S, Gupta A. The effect of fracture-related factors on the functional outcome at 1 year in distal radius fractures. Injury 2002; 33: 499-502.

28. Dixon S, Allen P, Bannister G. Which Colles' fractures should be manipulated? Injury 2005; 36 : $81-3$

29. Grewal R, MacDermid JC. The risk of adverse outcomes in extra-articular distal radius fractures is increased with malalignment in patients of all ages but mitigated in older patients. J Hand Surg Am 2007; 32: 962-70.

30. Pechlaner S, Gabl M, Lutz M et al. Distale Radius- frakturen - Atiologie, Behandlungsmethoden und Ergebnisse. Handchir Mikrochir Plast Chir 2007; 39: 19-28.

31. Wilcke MK, Abbaszadegan $H$, Adolphson PY Patient-perceived outcome after displaced distal radius fractures. A comparison between radiological parameters, objective physical variables, and the DASH score. J Hand Ther 2007; 20: 290-9.

32. Brogren E, Hofer M, Petranek M et al. Relationship between distal radius fracture malunion and arm related disability: a prospective population-based cohort study with 1-year follow-up. BMC Musculoskelet Disord 2011; 12: 9.

33. Jenkins NH, Mintowt-Czyz WJ. Mal-union and dys function in Colles' fracture. J Hand Surg [Br] 1988; 13: $291-3$.

34. Kumar S, Penematsa S, Sadri M et al. Can radiological results be surrogate markers of functional outcome in distal radial extra-articular fractures? Int Orthop 2008; 32: 505-9

35. Villar RN, Marsh D, Rushton $N$ et al. Three years after Colles' fracture. A prospective review. J Bone Joint Surg Br 1987; 69: 635-8

36. Solgaard S. Function after distal radius fracture. Acta Orthop Scand 1988; 59: 39-42.

37. Trumble TE, Schmitt SR, Vedder NB. Factors affecting functional outcome of displaced intraarticular distal radius fractures. J Hand Surg Am 1994; 19: 325-40

38. Karnezis IA, Panagiotopoulos E, Tyllianakis M et al. Correlation between radiological parameters and patient-rated wrist dysfunction following fractures of the distal radius. Injury 2005; 36: 1435-9.

39. Földhazy Z, Törnkvist H, Elmstedt E et al. Longterm outcome of nonsurgically treated distal radius fractures. J Hand Surg Am 2007; 32: 1374-84

40. Forward DP, Davis TRC, Sithole JS. Do young patients with malunited fractures of the distal radius inevitably develop symptomatic post-traumatic osteoarthritis? J Bone Joint Surg Br 2008; 90: 629-37

41. Ng CY, McQueen MM. What are the radiological predictors of functional outcome following fractures of the distal radius? J Bone Joint Surg $\mathrm{Br}$ 2011: 93: 145-50

42. Ilyas AM, Jupiter JB. Distal radius fractures - classification of treatment and indications for surgery. Hand Clin 2010; 26: 37-42

43. Horne JG, Devane P. Purdie G. A prospective randomized trial of external fixation and plaster cast immobilization in the treatment of distal radial fractures. J Orthop Trauma 1990; 4: 30-4.

44. Roumen RM, Hesp WL, Bruggink ED. Unstable Colles' fractures in elderly patients. A randomised trial of external fixation for redisplacement. J Bone Joint Surg Br 1991; 73: 307-11

45. Egol KA, Walsh M, Romo-Cardoso S et al. Distal radial fractures in the elderly: operative compared with nonoperative treatment. J Bone Joint Surg Am 2010; 92: 1851-7.

46. Arora R, Gabl M, Gschwentner M et al. A compara tive study of clinical and radiologic outcomes of unstable colles type distal radius fractures in patients older than 70 years: nonoperative treat ment versus volar locking plating. J Orthop Trauma 2009; 23: 237-42.
47. Kelly AJ, Warwick D, Crichlow TPK et al. Is manipulation of moderately displaced Colles' fracture worthwhile? A prospective randomized trial. Injury 1997: 28: 283-7.

48. Young BT, Rayan GM. Outcome following nonoperative treatment of displaced distal radius fractures in low-demand patients older than 60 years. $J$ Hand Surg Am 2000; 25: 19-28.

49. Jupiter JB, Ring D. Weitzel PP. Surgical treatment of redisplaced fractures of the distal radius in patients older than 60 years. J Hand Surg Am 2002; 27: 714-23.

50. Dayican A, Unal VS, Ozkurt B et al. Conservative treatment in intra-articular fractures of the dista radius: a study on the functional and anatomic outcome in elderly patients. Yonsei Med J 2003; 44: $836-40$

51. Anzarut A, Johnson JA, Rowe BH et al. Radiologic and patient-reported functional outcomes in an elderly cohort with conservatively treated distal radius fractures. J Hand Surg Am 2004; 29 : $1121-7$.

52. Jaremko JL, Lambert RGW, Rowe $\mathrm{BH}$ et al. Do radiographic indices of distal radius fracture reduction predict outcomes in older adults receiv ing conservative treatment? Clin Radiol 2007; 62: 65-72.

53. Barton T, Chambers C, Bannister G. A comparison between subjective outcome score and moderate radial shortening following a fractured distal radius in patients of mean age 69 years. J Hand Surg Eur Vol 2007: 32: 165-9.

54. Synn AJ, Makhni EC, Makhni MC et al. Distal radius fractures in older patients: is anatomic reduction necessary? Clin Orthop Relat Res 2009; 467: $1612-20$

55. Fujii $\mathrm{K}$, Henmi T, Kanematsu Y et al. Fractures of the distal end of radius in elderly patients: a comparative study of anatomical and functional results. J Orthop Surg (Hong Kong) 2002; 10: 9-15.

56. Diaz-Garcia RJ, Oda T, Shauver MJ et al. A systematic review of outcomes and complications of treating unstable distal radius fractures in the elderly. J Hand Surg Am 2011; 36: 824-35, e2.

57. Handoll HH, Madhok R. Conservative interventions for treating distal radial fractures in adults. Cochrane Database Syst Rev 2003; nr. 2: CD000314.

58. Brogren E, Hofer M, Petranek M et al. Fractures of the distal radius in women aged 50 to 75 years: natural course of patient-reported outcome, wrist motion and grip strength between 1 year and 2-4 years after fracture. J Hand Surg Eur Vol 2011; 36 568-76.

59. Sahu A, Charalambous CP. Mills SP et al. Reoperation for metalwork complications following the use of volar locking plates for distal radius fractures: a United Kingdom experience. Hand Surg 2011; 16: 113-8.

Mottatt 27.4. 2012, første revisjon innsendt 22.7. 2012, godkjent 20.12. 2012. Medisinsk redaktør Are Brean. 